\title{
Defense and protection mechanisms in lung exposed to asbestiform fiber: The role of macrophage migration inhibitory factor and heme oxygenase-1
}

\author{
Carla Loreto, ${ }^{1}$ Rosario Caltabiano, ${ }^{2}$ Adriana Carol Eleonora Graziano, ${ }^{3}$ Sergio Castorina, ${ }^{4}$ Claudia Lombardo, \\ Vera Filetti, ${ }^{1}$ Ermanno Vitale, ${ }^{5}$ Giuseppe Rapisarda, ${ }^{6}$ Venera Cardile, ${ }^{3}$ Caterina Ledda, ${ }^{5}$ Venerando Rapisarda ${ }^{5}$ \\ ${ }^{1}$ Anatomy and Histology, Department of Biomedical and Biotechnologies Sciences, University of Catania \\ ${ }^{2}$ Anatomic Pathology, Department of Medical and Surgical Sciences and Advanced Technologies G.F. Ingrassia, \\ University of Catania \\ ${ }^{3}$ Physiology, Department of Biomedical and Biotechnological Sciences, University of Catania \\ ${ }^{4}$ Anatomy, Department of Medical and Surgical Sciences and Advanced Technologies G.F. Ingrassia, University of \\ Catania \\ ${ }^{5}$ Occupational Medicine, Department of Clinical and Experimental Medicine, University of Catania \\ ${ }^{6}$ Department of Veterinary Prevention, ASP Catania, Italy
}

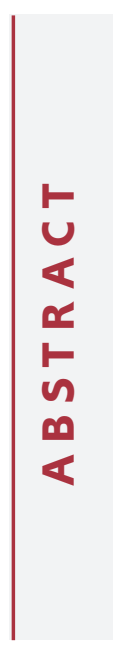

\begin{abstract}
Fluoro-edenite (FE), an asbestiform fiber, is responsible for many respiratory pathologies: chronic obstructive diseases, pleural plaques, fibrosis, and malignant mesothelioma. Macrophage migration inhibitory factor (MIF) is one of the first cytokines produced in response to lung tissue damage. Heme oxygenase-1 (HO-1) is a protein with protective effects against oxidative stress. It is up regulated by several stimuli including pro-inflammatory cytokines and factors that promote oxidative stress. In this research, the in vivo model of sheep lungs naturally exposed to FE was studied in order to shed light on the pathophysiological events sustaining exposure to fibers, by determining immunohistochemical lung expression of MIF and HO-1. Protein levels expression of HO-1 and MIF were also evaluated in human primary lung fibroblasts after exposure to FE fibers in vitro. In exposed sheep lungs, MIF and HO-1 immunoexpression were spread involving the intraparenchymal stroma around bronchioles, interstitium between alveoli, alveolar epithelium and macrophages. High MIF immunoexpression prevails in macrophages. Similar results were obtained in vitro, but significantly higher values were only detected for HO- 1 at concentrations of 50 and $100 \mu \mathrm{g} / \mathrm{mL}$ of FE fibers. MIF and HO-1 expressions seem to play a role in lung self-protection against uncontrolled chronic inflammation, thus counteracting the strong link with cancer development, induced by exposure to FE. Further studies will be conducted in order to add more information about the role of MIF and HO-1 in the toxicity FE-induced.
\end{abstract}

Key words: Asbestiform fiber; asbestos; inflammation; cytokines; fluoro-edenite; lung; cancer.

Correspondence: Dr. Caterina Ledda, Occupational Medicine, Department of Clinical and Experimental Medicine, University of Catania, Via Santa Sofia 87, 95123 Catania, Italy. E-mail: cledda@unict.it

Contributions: CLor and RC contributed equally to this work. CLor, RC, CLe, VR, concept and design of the experiments on human tissue; VC, ACEG, conceived, designed and performed the experiments on cell cultures; CLom, EV, GR, VF, performed the experiments; CLor, ACEG, SC, RC, data analysis; RC, VR, contributed reagents/materials/analysis tools; CLor, CLe, VC, manuscript drafting; SC, VR, manuscript revision. All the authors have read and approved the final version of the manuscript and agreed to be accountable for all aspects of the work.

Conflict of interest: The authors declare that they have no competing interests.

Funding: The authors have no support or funding to report.

Ethical Approval: Ante- and post-mortem examinations were conducted by a veterinary surgeon to establish the state of health of each sheep (according to Community Regulation CE n. 854/04 and council of 29 April 2004); the Ethical Committee of the University of Catania approved the study. 


\section{Introduction}

Occupational and environmental exposure to asbestos fibers can cause respiratory diseases. Epidemiologic studies have shown that exposure to asbestos fibers can produce pulmonary fibrosis (asbestosis), pleural abnormalities (effusion and plaques), and malignancies (bronchogenic carcinoma and mesothelioma). ${ }^{1,2}$ Extensive studies have recognized many important pathogenic mechanisms, yet the precise molecular mechanisms involved and the cross-talk between implicated pathways have not as yet been fully clarified..$^{2,3}$

Literature data have demonstrated that inhalation of asbestiform fibers can bring about various inter-connected pathogenetic lung diseases, represented by chronic inflammation and carcinogenesis. ${ }^{3-5}$ Previous investigations have analyzed fundamental pathologic changes following asbestos exposure, highlighting critical pathogenic pathways involving oxidative stress, apoptosis, and inflammation. ${ }^{5}$ In 1987, the International Agency for Research on Cancer (IARC) ${ }^{6}$ classified asbestos as a group 1 (definite) human carcinogen.

The term asbestos, as used herein, refers to a selected category of naturally occurring mineral silicate fibers, including chrysotile (the only serpentine fiber) and amphiboles (e.g., crocidolite, amosite, tremolite, anthophyllite, and actinolite).

However, several studies have documented the presence of other fibers that had not been classified amongst the asbestos ones. ${ }^{7,8}$ In particular, all over the world, scientists have found other naturally occurring asbestiform (NOA) fibers in specific geographic sites: Libby fiber, in Montana (USA); ${ }^{9}$ erionites, in Central Anatolia (Turkey); ${ }^{10}$ fluoro-edenite (FE), in Sicily (Italy). ${ }^{11}$ Of these, FE was the latest discovery and the least studied. ${ }^{12-21}$

$\mathrm{FE}\left(\mathrm{NaCa}_{2} \mathrm{Mg}_{5} \mathrm{Si}_{7} \mathrm{AlO}_{22} \mathrm{~F}_{2}\right)$ is a NOA fiber recognized and classified in 2001 by the Commission on New Minerals and Mineral Names (IMA: code 2000-049). Epidemiological studies have established its role in causing chronic obstructive lung disease ${ }^{22}$ and inflammation. ${ }^{12,13,15,21} \mathrm{FE}$ has been found as a contaminant of the bentonitic lavas of Mount Calvario's stone quarry, located in Biancavilla, a small town in Eastern Sicily (Italy). The material dug from the cave was used for about 50 years for building homes and paving roads. ${ }^{22,23}$

In Biancavilla, clusters of mortality from malignant mesothelioma (MM) were evidenced by epidemiological studies..$^{24,25}$

These fibers are similar in size and morphology to some amphibolic asbestos fibers (tremolite, actinolite, anthophyllite). ${ }^{23}$ Like asbestos, FE has been recognized by IARC as the causing agent of mesothelioma. ${ }^{26} \mathrm{FE}$ seems to provoke lung damage initially by involving the alveolar structures and subsequently the interstitium, inducing fibrosis. ${ }^{27}$ In particular, the primum movens occurs at the level of type I pneumocytes with the damage of the cytoplasmic membrane, resulting in loss of cell elements and in a series of reactions including macrophage activation, the release of growth factors and cytokines (IL-1 $\beta$; IL-6, and TNF- $\alpha$ ), metaplastic reconstruction of lung alveoli and fibrosis. ${ }^{28-32}$

FE fibers cause the generation of reactive oxygen species (ROS) and oxidative tissue damage that are involved in the pathogenesis of FE-induced cancers. ${ }^{27,30-32}$

Investigations of the ability of FE to induce cyto- and genotoxicity in monocyte-macrophage cell line via involvement of nitric oxide evidenced that inflammatory disorders appear to increase the risk of lung cancer. ${ }^{31,32}$ It is well known that hydroxyl radicals generated by asbestos fibers mediate inflammatory fibrosis of the lung and DNA damage that may ultimately result in lung carcinoma and mesothelioma. ${ }^{33}$

In a study on the mechanisms of asbestos fibers toxic action, it was observed that macrophage migration inhibitory factor (MIF) is one of the first cytokines produced in response to lung tissue damage and it is expressed by a wide variety of cell types, such as T lymphocytes, neutrophils, macrophages, endothelial cells and fibroblasts. ${ }^{34}$ Stimulation of macrophages with the pro-inflammatory cytokines TNF- $\alpha$ triggers MIF release ${ }^{34}$ that promotes sustained phosphorylation of the ERK1/2 MAPK cascade, ${ }^{35}$ leading to pro-proliferative effect, playing a role in alveolar repair. ${ }^{36}$

Heme oxygenase-1 (HO-1), a $32-\mathrm{kDa}$ protein, is the inducible $\mathrm{HO}$ isoform. It is up-regulated by several stimuli including proinflammatory cytokines and factors that promote oxidative stress. ${ }^{37,38} \mathrm{HO}-1$ protects against oxidative stress and inflammation-induced injury. ${ }^{37,38} \mathrm{HO}-1$ is expressed in many lung cell types including alveolar macrophages, bronchial epithelial cells, and alveolar epithelial cells. ${ }^{39}$

Literature data suggest a role of HO-1 in acute and chronic phases in asbestos-induced oxidative stress lung injury. ${ }^{40}$

In the present research, we focused our attention on the biological effects due to FE fibers exposure. This study has been conducted on an in vivo model of sheep lungs naturally exposed to FE in order to keep insight into the pathophysiological events sustaining fibers exposure by studying the immunohistochemical lung expression of MIF and $\mathrm{HO}-1$.

Expression of HO-1 and MIF protein levels were also detected in human primary lung fibroblasts after exposure to growing concentrations of FE fibers in order to confirm and add more data on molecular/cellular aspects.

\section{Materials and Methods}

\section{Animals}

Sixty sheep of both sexes $(\mathrm{n}=60)$, randomly selected from six exposed flocks $(n=360)$ habitually grazing $3 \mathrm{~km}$ from the town of Biancavilla and ten control sheep $(n=10)$, from a flock $(n=60)$ habitually grazing about $50 \mathrm{~km}$ from the Biancavilla stone quarry, were sacrificed in a slaughterhouse and used for this study as previously described. ${ }^{25,41}$ Ante and post mortem examinations were conducted by a veterinary surgeon to establish the state of health of each sheep (according to Community Regulation CE n. 854/04 and council of 29 April 2004). The age range of exposed and control animals was 4.0-6.5 years.

\section{Histology}

Lung tissue $\left(1 \mathrm{~cm}^{3}\right)$ from the right apical lobe and the main and accessory lung lobes were rinsed in phosphate buffered saline (PBS), fixed in $10 \%$ buffered-formalin as previously described. ${ }^{42}$ After an overnight wash, specimens were dehydrated in graded ethanol, cleared in xylene and paraffin-embedded, preserving their anatomical orientation. Sections (4-5 $\mu \mathrm{m}$ in thickness) were cut from paraffin blocks using a microtome, mounted on sialinatecoated slides and stored at room temperature. The sections were then stained with hematoxylin and eosin (H\&E) and examined using a Zeiss Axioplan light microscope (Carl Zeiss, Oberkochen, Germany) for general morphological characterization and to highlight the presence or absence of structural alterations. Finally, representative photomicrographs were captured using a digital camera (AxioCam MRc5, Carl Zeiss).

\section{Immunohistochemistry}

Lung tissues were fixed in $10 \%$ buffered formalin for $2 \mathrm{~h}$; after an overnight wash, specimens were dehydrated in graded ethanol and paraffin-embedded. Sections 3-4 $\mu \mathrm{m}$ in thickness were cut, mounted on silane-coated slides (Dako, Glostrup, Denmark) and air-dried. For immunohistochemical analysis, specimens were 
processed as previously described. ${ }^{43}$ Briefly, the slides were dewaxed in xylene, hydrated using graded ethanol and incubated for $30 \mathrm{~min}$ in $0.3 \% \mathrm{H}_{2} \mathrm{O}_{2} /$ methanol solution to quench endogenous peroxidase activity and then rinsed for 20 min with PBS (SigmaAldrich, Milan, Italy). Antigen retrieval was performed using a microwave oven $(750 \mathrm{~W})(5 \mathrm{~min} \times 3)$ in capped polypropylene slide-holders with citrate buffer $(10 \mathrm{mM}$ citric acid, $0.05 \%$ Tween 20, pH 6.0; Bio-Optica, Milan, Italy). The blocking step was performed before the application of the primary antibody with $5 \%$ bovine serum albumin (BSA; Sigma-Aldrich) in PBS for $1 \mathrm{~h}$ in a humid chamber. BSA was used as a blocking agent to prevent nonspecific binding of the primary and secondary antibodies to the tissue sections. Following blocking, the sections were incubated overnight at $4{ }^{\circ} \mathrm{C}$ with a rabbit polyclonal anti-HO-1 antibody and a rabbit polyclonal anti-MIF antibody (PA5-27338 and PA5-27343 respectively, Thermo Fisher Scientific, Waltham, MA, USA), both diluted 1:100 in PBS. Immune complexes were then treated with a biotinylated antibody and then detected with peroxidase- labeled streptavin, both incubated for $10 \mathrm{~min}$ at room temperature (LSAB+ System-HRP, K0690; Dako). The immunoreaction was visualized by incubating the sections for $2 \mathrm{~min}$ in a $0.1 \% 3,3^{\text {' }}$-diaminobenzidine and $0.02 \%$ hydrogen peroxide solution (DAB substrate Chromogen System; Dako). The sections were lightly counterstained with Mayer's hematoxylin (Histolab Products AB, Göteborg, Sweden) mounted in GVA (Zymed Laboratories, San Francisco, CA, USA) and observed with an Zeiss Axioplan light microscope and photographed with a digital camera (AxioCam MRc5; Carl Zeiss Microscopy GmbH, Jena, Germany).

\section{Evaluation of immunohistochemistry}

The HO-1 and MIF antibody-staining status were identified as either negative or positive. Immunohistochemical positive staining was defined by the presence of brown chromogen on the edge of the hematoxylin-stained cell nucleus, distributed within the cytoplasm or in the membrane via evaluation by light microscopy as previously described. ${ }^{43}$

Positive and negative controls were performed to test the specific reaction of the primary antibody used in this study at a protein level. Positive controls consisted of tissue specimens with known antigenic positivity. Sections treated with PBS without primary antibodies served as negative controls. Seven fields, the area of which was about $600,000 \mu \mathrm{m}^{2}$, randomly selected from each section, were analyzed for morphometric and densitometric analysis. The areas percentage (morphometric analysis) stained with $\mathrm{HO}-1$ and MIF antibodies, was expressed as percentage of positive dark brown pixels present in the analyzed fields. The level (high/low) of staining intensity of positive areas (densitometric analysis) was expressed as densitometric count ( $\mathrm{pixel}^{2}$ ) of positive, dark brown pixels of the analyzed fields. The data were calculated using the software for image acquisition AxioVision Release 4.8.2 - SP2 (Carl Zeiss), and expressed as mean \pm SD. Statistical significance of results was thus accomplished. Digital micrographs were taken using the Zeiss Axioplan light microscope (Carl Zeiss) fitted with a digital camera (AxioCam MRc5; Carl Zeiss); three blinded investigators, whose assessments were assumed correct if values were not significantly different, made evaluations. In case of dispute concerning interpretation, the case was reconsidered to reach a unanimous agreement.

\section{Human fibroblasts cultures and treatments}

Primary lines of normal, non-immortalized, human adult lung fibroblasts were kindly provided by Prof. Carlo Vancheri (Department of Clinical and Experimental Medicine, University of Catania, Italy). Human lung fibroblasts were grown in DMEM containing $10 \%$ fetal calf serum, $100 \mathrm{U} / \mathrm{mL}$ penicillin and
$100 \mu \mathrm{g} / \mathrm{mL}$ streptomycin (Sigma-Aldrich) and incubated at $37^{\circ} \mathrm{C}$ and $5 \% \mathrm{CO}_{2}$. The medium was changed every three days and subcultures were performed every 10-12 days. In all experiments, cells at a passage earlier than the tenth were used.

FE from Biancavilla was suspended in culture medium and after sonication, added to the experimental cultures at concentrations of 10,50 and $100 \mu \mathrm{g} / \mathrm{mL}\left(1.06,10.6\right.$, and $\left.21.2 \mu \mathrm{g} / \mathrm{cm}^{2}\right)$ for 72 $\mathrm{h}$ before cell harvesting.

\section{Western blot}

Western blot analysis was performed as already reported by Graziano et al. ${ }^{44}$ Untreated or FE-treated human fibroblast cultures were scraped, transferred into $50 \mathrm{~mL}$ conical tubes and centrifuged at $1500 \times \mathrm{g}$ for $5 \mathrm{~min}$. After twice washing with 1x PBS, the pellets were treated with lysing buffer M-PER Mammalian Protein Extraction Reagent (Pierce, Fisher Scientific, Milan, Italy) and vortexed for $30 \mathrm{~min}$ on ice. The protein lysates were centrifuged at $15,000 \times \mathrm{g}$ for $15 \mathrm{~min}$ at $4^{\circ} \mathrm{C}$. The supernatants were transferred into a new tube and the protein quantification was performed by the bicinchoninic acid assay (BCA assay; Pierce, Fisher Scientific). Equal amounts of proteins $(30 \mu \mathrm{g})$ were separated by $4-$ $12 \%$ Bolt gel electrophoresis (Thermo Fisher Scientific) and transferred into transfer stacks of nitrocellulose (Thermo Fisher Scientific) by iBlot Gel Transfer Device (Thermo Fisher Scientific, Waltham). The membranes were stained with Ponceau S solution to verify transfer efficiency. The immunodetection steps were automated by iBind Flex Western System device (Thermo Fisher Scientific), according to manufacturer's instruction. The following antibodies were applied: the rabbit polyclonal anti-HO-1 antibody and the rabbit polyclonal anti-MIF antibody, both at 1:500 dilution (PA5-27338 and PA5-27343 respectively, Thermo Fisher Scientific) and the mouse monoclonal anti- $\alpha$-tubulin (T9026, Sigma-Aldrich) at 1:5000 dilution. The goat anti-rabbit and the goat anti-mouse IgG-HRP were from Santa Cruz Biotechnology, Milan, Italy. The detection step was performed using an enhanced chemiluminescent solution (Pierce, Fisher Scientific) and the Uvitec Alliance LD9 imaging system (Uvitec, Cambridge, UK). Densitometrical analysis and the relative quantification were performed by UVITEC Alliance software (Uvitec). Values were expressed as a percentage of volume respect to unexposed cell (control) corrected by loading control volume of each sample. Experiments were performed in triplicate.

\section{Statistical analysis}

Statistical analysis was performed using GraphPad Prism 7 (GraphPad Software, Inc., La Jolla, CA, USA). Unpaired $t$-test with Mann Whitney test was used and P-values of less than 0.05 $(\mathrm{P}<0.05)$ were considered statistically significant. Western blot assays were performed three times and the results represented as mean \pm SD of the percentage of HO-1 and MIF proteins with respect to untreated cells. Western blot data analysis was done using one-way ANOVA with multiple comparisons testing respect to untreated cells.

\section{Results}

\section{Histology}

The histopathological examination (H\&E; not shown) demonstrated the presence of FE fibers that were scattered in the lung tissue of exposed sheep, in close contact with alveolar epithelium and interstitium as already reported in our previous studies. ${ }^{27-29,45-47}$ The analysis showed a fibrotic interstitium accompanied by a thickening of the bronchiolar mucosa. The alveolar walls were also dam- 
aged by the reactive process and showed clusters of FE fibers. These histological alterations were greater where FE fibers were deposited.

\section{Immunohistochemistry}

Immunohistochemistry (HIC) evaluation demonstrated the expression of both HO-1 and MIF in the lung tissue of sheep exposed to FE fibers. In Figure 1 are reported the images of lung tissue sections of exposed and not exposed sheeps.

\section{Densitometric and morphometric analyses}

Densitometric and morphometric analyses of HO-1 and MIF stained areas, evaluated in the lung tissue of not exposed sheeps, demonstrated that non-significant traces of HO-1 and MIF immunostaining were present (Figures 1 and 2).

In exposed sheep lung, an immunoexpression of MIF was spread throughout the tissue, involving the intra-parenchymal stroma around bronchioles, the interstitium between alveolar epithelium, and macrophages (Figure 1 A2). Exposed sheep lung showed also a high HO-1 immunoexpression involving also the intraparenchymal stroma around bronchioles and the interstitium between the alveolar epithelium (Figure 1 B2).

From the densitometric analysis of the level of staining intensity of positive areas, expressed as densitometric count $\left(\mathrm{pixel}^{2}\right)$ of positive dark brown pixels of the analyzed fields, revealed that in exposed lungs the strong MIF and $\mathrm{HO}-1$ immunostaining were similar $(\mathrm{P}<0.05)$; more intense immunostaining of MIF was particularly high in macrophages (Figure 1 A3). For the morphometric analysis, the percentage of positive dark brown pixels present in the analyzed field of HO-1 and MIF immunostained area was considered. From the immunolabeling extension analysis, the percentage of HO-1 and MIF immunostained areas were very much higher in exposed lungs compared with the not exposed ones $(\mathrm{P}<0.05)$, in which no sign of immunostaining was identified by the software used for image analysis (Figure 3).

Sections used as a negative control for IHC, treated with PBS and without the primary antibody, showed no HO-1 and MIF immunostaining, as expected (data not shown).

\section{Expression of HO-1 and MIF protein levels in human primary lung fibroblasts}

The HO-1 and MIF protein levels were evaluated in fibroblasts exposed to 10,50 and $100 \mu \mathrm{g} / \mathrm{mL}$ of FE fibers for $72 \mathrm{~h}$, in order to confirm in vitro the results obtained in vivo and verify if data from animal samples could be extended to humans. The concentrations were selected within the range used by us and many other authors for asbestos fibers. ${ }^{30-32}$ The length of the fibers ranged from 12 to $40 \mu \mathrm{m}$, and diameters ranged from 0.4 to $1 \mu \mathrm{m} .{ }^{11}$

As shown in Figure 4 A,B a marked and concentration-dependent increase of HO-1 protein expression was observed in fibroblasts incubated with FE, respect to the unexposed controls. Specifically, the cells treated with $10 \mu \mathrm{g} / \mathrm{mL}$ of FE reported a slightly and non-significant change in $\mathrm{HO}-1$ protein expression compared with the untreated cells. However, the induction of significantly higher protein levels of HO-1 was reported following FE exposure at concentrations of 50 and $100 \mu \mathrm{g} / \mathrm{mL} \quad(* \mathrm{P}<0.05$; ${ }^{*} \mathrm{P}<0.01$; Figure $\left.4 \mathrm{~B}\right)$. As about MIF protein, its basal level was very low in human untreated fibroblasts and a weak non-significant increase was detected (Figure 4C) in presence of FE, suggesting that in vivo a more complex interaction sustained by communication of different cell types should be at play.

\section{Discussion}

Epidemiological studies have shown that exposure to FE correlates directly with increased pulmonary chronic obstructive diseases and morbidity and mortality..$^{23-26}$

However, the mechanisms by which the fibers may cause cellular and molecular toxicity are still not clearly known. ${ }^{48-54}$ To gain further insight into the defense and protection mechanisms and to follow up on our previous studies, we investigated MIF and HO-1 immunohistochemical in vivo expression using sheep lungs, which are comparable in architecture, volume and respiratory physiological parameters to human lungs. ${ }^{55}$ Therefore, the sheep model of asbestosis is an excellent tool to elucidate the pathophysiology of interstitial lung activity. ${ }^{27}$

Asbestos fibers are known to induce biological effects in association with the production of ROS and corresponding cellular injury by the oxidation of proteins and DNA after exposure. ${ }^{8}$ These effects, in turn, mediate inflammatory fibrosis of the lung with inflammatory cytokines release, stress response and DNA damage, which may ultimately result in lung carcinoma and MM.,33 The persistence inflammation leads to increased pulmonary damage and contributes to the onset of chronic pulmonary diseases. ${ }^{8}$

In this contest, MIF plays a role in the response of a wide range of models of tissue injury. Its activity is associated with tissue repair, ${ }^{56-59}$ cell proliferation, protection from apoptotic stimuli. ${ }^{60-63}$ In particular, several researchers have concentrated their efforts on studying MIF role in lung injury and repair..$^{57,61-63}$ As other cytokines, MIF is produced in response to lung tissue damage and the inflammatory response triggers MIF release by macrophages. ${ }^{34}$ Due to the pro-proliferative effects, MIF plays a role in alveolar repair by starting alveolar epithelial type II (AEC-II) proliferation and hyperplasia followed by differentiation into AEC-I, restoring the air-blood barrier.

In response to FE exposure, our results underline an immunoexpression of MIF in sheep lungs interalveolar stroma, around bronchioles, and in macrophages. While only a slight (non-significant) increase of MIF expression was observed in human primary lung fibroblasts exposed at higher concentrations (50 and 100 $\mu \mathrm{g} / \mathrm{mL}$ ) of FE fibers. Thus, it can be assumed that in vivo after inhaled FE reaches the peripheral air spaces, where it is incorporated by activated alveolar macrophages, causing the release of MIF and triggering an inflammatory response in a more complex interaction sustained by communication of different cell types, not observable in vitro. On the other hand, MIF was found in media of fibroblast cell lines that were continuously growing. Its release was dependent on activation of the cells to enter the mitotic cycle, particularly on cells in S phase. When fibroblasts were contact inhibited little or no MIF was found in media.

FE migration and macrophage activation damage adjacent cells, including AEC-I, disrupting epithelial integrity and facilitating the spread of growth factors and cytokines to the interstitium. As part of the healing process, AEC-II undergoes hyperplasia followed by interstitial fibrosis. ${ }^{64}$ In this scenario, MIF, released in the alveolar compartment by macrophages, may represent the principal actor that moves to epithelial proliferation and may contribute to alveolar repair, representing a defense mechanism against FE insult; even though MIF, being released by macrophages, may be involved also in fibroblast fibrogenic response.

Another molecule that seems to act with a protective role is HO-1. Several studies have shown a protective function of this inducible enzyme against lung injury. ${ }^{37,38}$ Over the past decade, there has been increased documentation of the role of HO-1 in tumorigenesis and cancer progression. ${ }^{65}$

In response to FE exposure, our results underline a significantly increase of HO-1 expression in human primary lung fibroblasts 
exposed at higher concentration (50 and $100 \mu \mathrm{g} / \mathrm{mL})$ of $\mathrm{FE}$ fibers and an in vivo HO-1 immunoexpression in sheep lung interalveolar stroma (involving alveolar epithelium and macrophages), around bronchioles. These data support the concept that changes in the cellular redox status brought on by cigarette smoke induce HO-1 in fibroblasts. Although some published data have shown that changes in the cellular redox status brought on by cigarette smoke induce
HO-1 in fibroblasts, further new studies have been planned to evaluate the effects of FE also on monocyte/macrophage lines. Moreover, since the depletion in GSH, ascorbic acid and alteration in GSH redox system enzymes was observed in fibrosis and carcinogenesis induced by chrysotile, but never by FE, it would be appropriate to investigate the changes in the oxidative status FE-induced and their involvement in the FE negative biological effects.
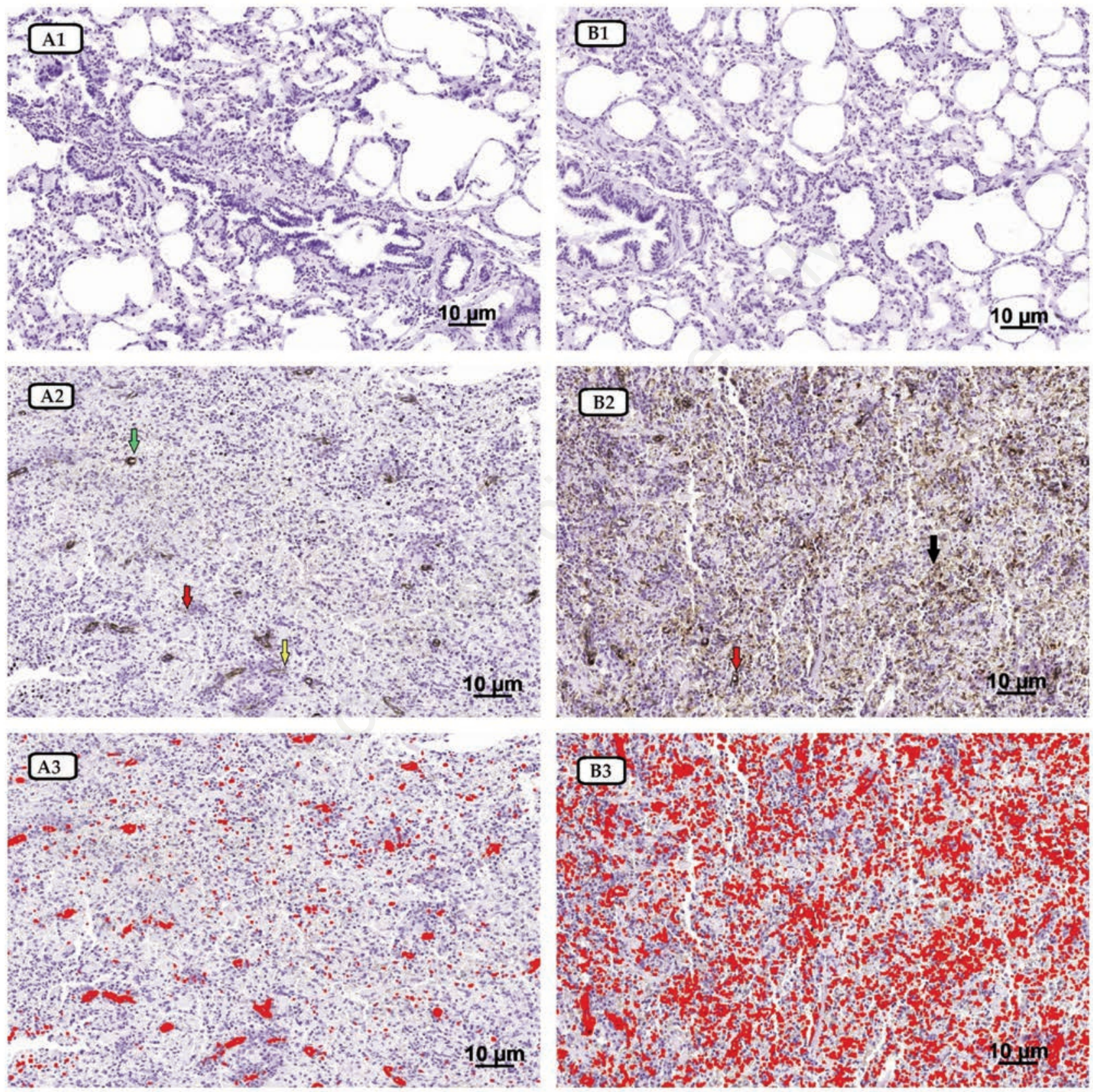

Figure 1. A1) MIF IHC section of non-exposed sheep (magnification 200x). A2) MIF IHC section of exposed sheep; the fibrotic interstitium showed a strong scattered immunoreaction; green arrow indicates the intra-parenchymal stroma around a bronchiolar structure, yellow arrow shows MIF macrophages immunodetection while red arrow indicates FE deposit fibers (magnification 200x). A3) MIF immunostaining software image analysis of panel $\mathrm{A} 2$, in which mainly a high immunostained area (red color) was detected (magnification 200x). B1) HO-1 IHC section of non-exposed sheep (magnification 200x). B2) HO-1 IHC section of exposed sheep; in the lung fibrotic tissue, a strong and widespread immunostaining was demonstrated throughout the interstitium (black arrow) and bronchiolar structures (red arrow) (magnification 200x). B3) HO-1 immunostaining software image analysis of panel B2, in which mainly a high immunostained area (red color) was detected (magnification 200x). 
HO-1 overexpression has been demonstrated to prevent DNA damage and cell transformation; ${ }^{66}$ however, in the later stages of tumorigenesis HO-1 enhances growth and survival of cancer cells. ${ }^{67-69}$ HO-1 is upregulated by pro-inflammatory cytokines that promote oxidative stress. It catalyzes the oxidation of heme into three reaction products: biliverdin, carbon monoxide $(\mathrm{CO})$ and iron. ${ }^{70,71}$ Biliverdin turns into bilirubin that is a powerful antioxidant. ${ }^{72,73} \mathrm{CO}$ has anti-proliferative effects and anti-inflammatory properties in response to pathological injury. ${ }^{74}$ Labile iron induces the production of ferritin that binds iron deposits, thus reducing the oxidative stress and playing an important role in the antioxidant response to ironmediated ROS generation. ${ }^{75}$ Some investigations on FE exposure on sheep model were carried. Martinez et al. ${ }^{27}$ investigated the pathological consequences of the inhalation of FE fibers, connected to apoptotic processes and histological alterations of lung structure through the expression of TNF-related apoptosis inducing ligand (TRAIL) and its receptor DR5, and of MMP-13 implicated in the breakdown of extracellular matrix. Furthermore observed the over expression of the MMP-13, mainly in fibroblasts and epithelial cells, suggestive of its association in the loss of the lung architecture. Moreover, the expression of TRAIL and its receptor was observed in areas of inflammatory infiltration and active fibrosis (alveolar surfaces), which confirmed the link between FE and epithelial cell apoptosis at the site of initial fiber deposition in the bronchioalveolar duct region. Loreto et al. ${ }^{29}$ identified the immunohistochemical localization of bcl-2 and bax, correspondingly anti- and pro-apoptotic proteins. Low bcl-2 immunoreactivity and bax up-regulation was

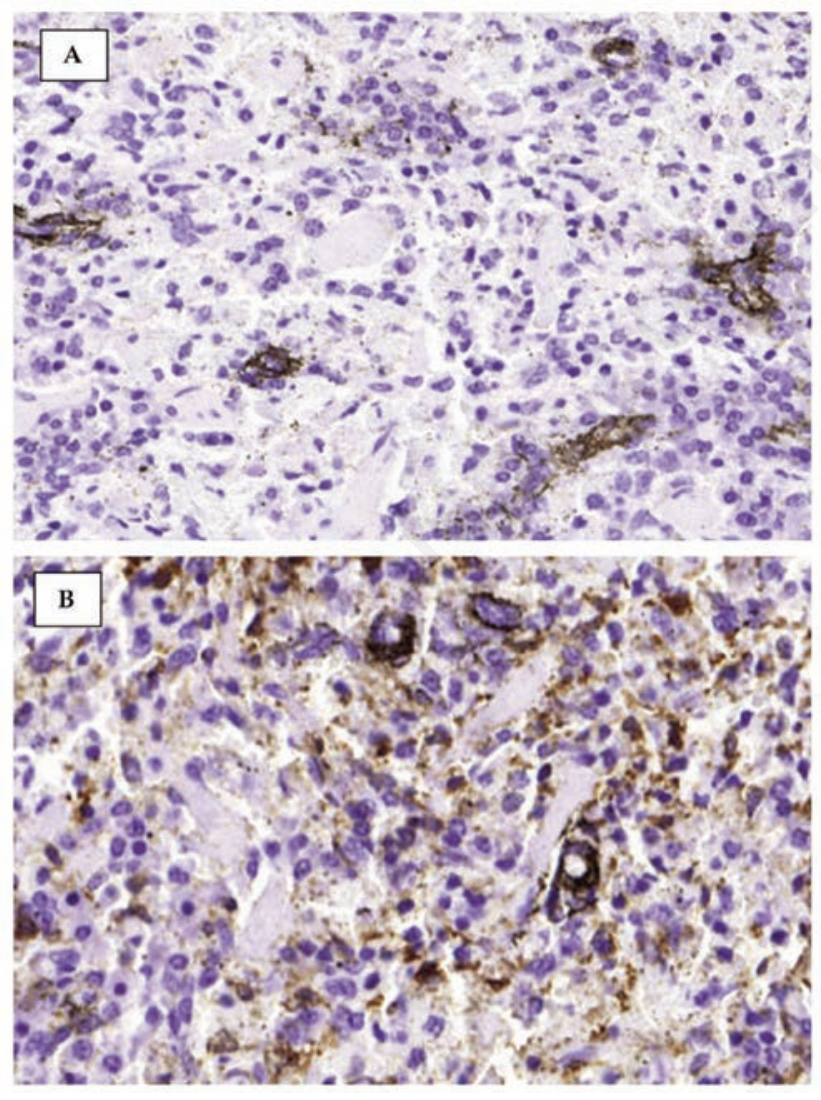

Figure 2. A) Higher magnification of MIF immunohistochemical expression in exposed sheep section (magnification 400x). B) Higher magnification of $\mathrm{HO}-1$ immunohistochemical expression in exposed sheep section (magnification 400x).

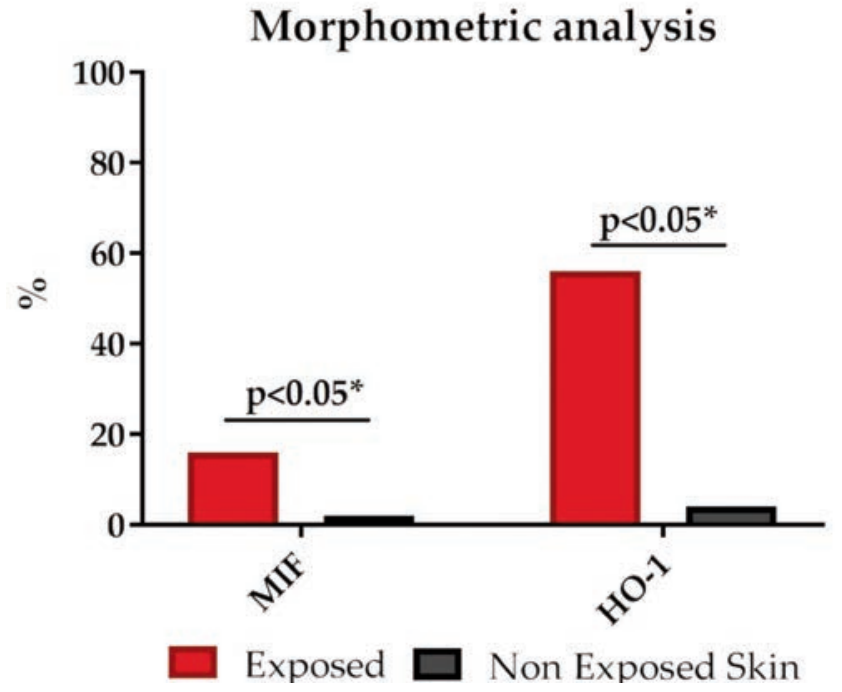

Figure 3. Morphometric analysis for MIF and HO-1 in exposed and not exposed sheep.

A
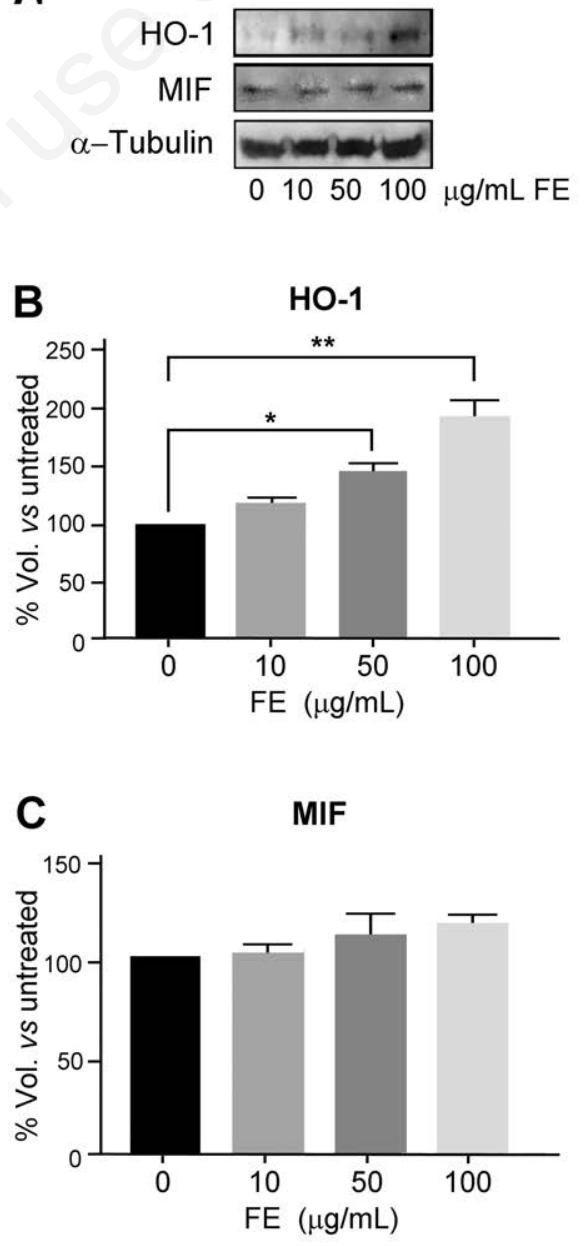

Figure 4. HO-1 and MIF protein levels in human primary lung fibroblasts unexposed or FE-exposed for $72 \mathrm{~h}$. Representative immunoblotting of HO-1 and MIF expressions (A). Results of three independent immunoblots are represented as percentage of HO-1 (B) and MIF (C) proteins with respect to untreated cells $\left({ }^{*} \mathbf{P}<0.05 ;{ }^{* *} \mathbf{P}<0.01\right.$ compared to control). 
observed, demonstrating that apoptosis is an important mechanism for removing cells with irreparable FE induced genetic changes that predispose them to a neoplastic evolution. Another study using an in vivo sheep model was performed by Musumeci et al.,$^{52}$ who studied the overexpression of the phosphorylated retinoblastoma protein $(\mathrm{pRb})$ in alveolar epithelium and interstitium, close to the FE fibers, suggesting that the up-regulation of $\mathrm{pRb}$ could be a programmed response to protect the organism against uncontrolled cell proliferation. Finally, the overexpression of Fibulin-3 in lung of sheep suggested that the Fibulin-3 may reflect a defensive response of the tissues after exogenous stimuli and may be implicated in cancer development, especially in the context of FE contamination. ${ }^{18}$ FE fibers are recognized as responsible for acute oxidative stress and inflammation that persist over time and contribute to chronic fibrosis, MM and probably lung cancer. ${ }^{12-13,22-26}$

Similarly, asbestos-like fibers, i.e. as Libby fibers, have already been shown to cause HO-1 up-regulation, both in vivo and in vitro, ${ }^{39-40}$ suggesting a preeminent role of this enzyme in acute and chronic inflammation, in response to asbestos-induced oxidative stress and lung injury. ${ }^{40,75-76}$

The results of this study demonstrated an HO-1 diffuse increased expression in lungs exposed to $\mathrm{FE}$ fibers, suggesting a reactive defense mechanism of this organ against FE fibers insult. Furthermore, in vitro studies demonstrated a correlation between the level of ROS production and HO-1 expression. ${ }^{39}$

The fibers themselves and ROS are known to induce an inflammatory cytokine release by $\mathrm{FE},{ }^{13,15,28}$ causing the recruitment of inflammatory neutrophils in an attempt to clear the foreign fiber. ${ }^{77,78}$

Inflammatory cells and mediators are essential components in the tumor microenvironment and play decisive roles in the initiation, promotion, and progression of cancer.

The present research highlights for the first time protective and defensive mechanisms after lung injury in an animal model exposed to $\mathrm{FE}$ that can simulate biological behavior in human lung tissue. MIF and HO-1 expression seem to play a role in lung self-protection against uncontrolled chronic inflammation and thus counteracting the strong link with cancer development. Even if the cancerogenic role of FE has been already demonstrated, ${ }^{26}$ the relationships occurring between the documented results and development of pleural malignancies remain to be furtherly ascertained.

Understanding these action mechanisms seems to be essential both for determining induced effects after lung exposure to FE and for preventing tumorigenesis, as well as for defining new therapeutical approaches. Naturally, further studies will be conducted in vitro and in vivo in order to add more information about FE toxicity pathways.

\section{Acknowledgments}

The authors are grateful to Elisabetta Pricoco for her collaboration in the research.

\section{References}

1. Kamp DW. Asbestos-induced lung diseases: An update. Transl Res 2009;153:143-52.

2. Kamp DW, Mossman BT. Asbestos-associated cancers: Clinical spectrum and pathogenic mechanisms. Clin Occ Envir Med 2002 2:753-77.

3. Kamp DW, Weitzman SA. The molecular basis of asbestos induced lung injury. Thorax 1999;54:638-52.
4. Liu G, Beri R, Mueller A, Kamp DW. Molecular mechanisms of asbestos-induced lung epithelial cell apoptosis. Chem Biol Interact 2010;188:309-18.

5. Liu G, Cheresh P, Kamp DW. Molecular basis of asbestosinduced lung disease. Ann Rev Pathol 2013;8:161-87.

6. WHO, International Agency for Research on Cancer. Overall evaluations of carcinogenicity: An updating of IARC monographs volumes 1 to 42 . IARC monographs on the evaluation of carcinogenic risks to humans. Supplement 1987;7:1-440.

7. Miozzi E, Rapisarda V, Marconi A, Costa C, Polito I, Spandidos DA, et al. Fluoro-edenite and carbon nanotubes: The health impact of 'asbestos-like' fibers. Exp Ther Med 2016;11:21-7.

8. Sanchez VC, Pietruska JR, Miselis NR, Hurt RH, Kane AB. Biopersistence and potential adverse health impacts of fibrous nanomaterials: What have we learned from asbestos? Wiley Interdiscip Rev Nanomed Nanobiotechnol 2009;1:511-29.

9. Meeker GP, Bern AM, Brownfield IK, Lowers HA, Sutley SJ, Hoefen TM, et al. The composition and morphology of amphiboles from the rainy creek complex, near libby, montana. Am Mineralog 2003;88:1955-69.

10. Baris I, Artvinli M, Saracci R, Simonato L, Pooley F, Skidmore $\mathrm{J}$, et al. Epidemiological and environmental evidence of the health effects of exposure to erionite fibres: A four-year study in the cappadocian region of turkey. Int J Cancer 1987;39:10-7.

11. Gianfagna A, Oberti R. Fluoro-edenite from Biancavilla (Catania, Sicily, Italy): Crystal chemistry of a new amphibole end-member. Am Mineralog 2001;86:1489-93.

12. Ledda $\mathrm{C}$, Caltabiano R, Loreto $\mathrm{C}$, Cinà D, Senia $\mathrm{P}$, Musumeci A, et al. Prevalence of anti-nuclear autoantibodies in subjects exposed to natural asbestiform fibers: A cross-sectional study. J Immunotoxicol 2018;15:24-8.

13. Ledda C, Costa C, Matera S, Puglisi B, Costanzo V, Bracci M, et al. Immunomodulatory effects in workers exposed to naturally occurring asbestos fbers. Mol Med Rep 2017; 15:3372-8.

14. Ledda C, Loreto C, Bracci M, Mangano D, Migliore M, Ricceri $\mathrm{V}$, et al. High risk of pleural plaques and parenchymal abnormalities in women living in Biancavilla (Italy). Future Oncol 2016;12:63-5.

15. Ledda C, Loreto C, Matera S, Massimino N, Cannizzaro E, Musumeci A, et al. Early effects of fluoro-edenite: Correlation between il-18 serum levels and pleural and parenchymal abnormalities. Future Oncol 2016;12:59-62.

16. Ledda C, Loreto C, Pomara C, Rapisarda G, Fiore M, Ferrante $\mathrm{M}$, et al. Sheep lymph-nodes as a biological indicator of environmental exposure to fluoro-edenite. Environ Res 2016;147:97-101.

17. Ledda C, Pomara C, Bracci M, Mangano D, Ricceri V, Musumeci A, et al. Natural carcinogenic fiber and pleural plaques assessment in a general population: A cross-sectional study. Environ Res 2016;150:23-9.

18. Rapisarda V, Caltabiano R, Musumeci G, Castrogiovanni P, Ferrante M, Ledda C, et al. Analysis of fibulin-3 after exposure to asbestos-like fibers. Environ Res 2017;156:381-7.

19. Rapisarda V, Ledda C, Migliore M, Salemi R, Musumeci A, Bracci $\mathrm{M}$, et al. Fbln-3 as a biomarker of pleural plaques in workers occupationally exposed to carcinogenic fibers: A pilot study. Future Oncol 2015;11:35-7.

20. Rapisarda V, Ledda C, Ricceri V, Arena F, Musumeci A, Marconi A, et al. Detection of pleural plaques in workers exposed to inhalation of natural fluoro-edenite fibres. Oncol Lett 2015;9:2046-52.

21. Rapisarda V, Loreto C, Castorina S, Romano G, Garozzo SF, Musumeci A, et al. Occupational exposure to fluoro-edenite and prevalence of anti-nuclear autoantibodies. Future Oncol 2018;14:59-62. 
22. Biggeri A, Pasetto R, Belli S, Bruno C, Di Maria G, Mastrantonio M, et al. Mortality from chronic obstructive pulmonary disease and pleural mesothelioma in an area contaminated by natural fiber (fluoro-edenite). Scand J Work Environ Health 2004;30:249-52.

23. Comba P, Gianfagna A, Paoletti L. Pleural mesothelioma cases in Biancavilla are related to a new fluoro-edenite fibrous amphibole. Arch Environ Health 2003;58:229-32.

24. Soffritti M, Minardi F, Bua L, Degli Esposti D, Belpoggi F. First experimental evidence of peritoneal and pleural mesotheliomas induced by fluoro-edenite fibres present in Etnean volcanic material from Biancavilla (Sicily, Italy). Eur J Onc 2004:9:169-75.

25. Paoletti L, Bruni BM, Arrizza L, Mazziotti-Tagliani S, Pacella, A. A micro-analytical sem-eds method applied to the quantitative chemical compositions of fibrous amphiboles. Per Mineralog 2008;77:63-73.

26. Grosse Y, Loomis D, Guyton KZ, Lauby-Secretan B, El Ghissassi F, Bouvard V, et al. Carcinogenicity of fluoro-edenite, silicon carbide fibres and whiskers, and carbon nanotubes. Lancet Oncol 2014:15:1427-8.

27. Martinez G, Loreto C, Rapisarda V, Musumeci G, Valentino M, Carnazza ML. Effects of exposure to fluoro-edenite fibre pollution on the respiratory system: An in vivo model. Histol Histopathol 2006;21:595-601

28. Loreto C, Carnazza ML, Cardile V, Libra M, Lombardo L, Malaponte G, et al. Mineral fiber-mediated activation of phosphoinositide-specific phospholipase $\mathrm{c}$ in human bronchoalveolar carcinoma-derived alveolar epithelial a549 cells. Int J Oncol 2009;34:371-6.

29. Loreto C, Rapisarda V, Carnazza ML, Musumeci G, Valentino $\mathrm{M}$, Fenga $\mathrm{C}$, et al. Fluoro-edenite fibres induce lung cell apoptosis: An in vivo study. Histol Histopathol 2008;23:319-26.

30. Travaglione S, Bruni B, Falzano L, Paoletti L, Fiorentini C. Effects of the new-identified amphibole fluoro-edenite in lung epithelial cells. Toxicol in Vitro 2003;17:547-52.

31. Cardile V, Proietti L, Panico A, Lombardo L. Nitric oxide production in fluoro-edenite treated mouse monocyte-macrophage cultures. Oncol Rep 2004;12:1209-15.

32. Cardile V, Renis M, Scifo C, Lombardo L, Gulino R, Mancari $\mathrm{B}$, et al. Behaviour of the new asbestos amphibole fluoro-edenite in different lung cell systems. Int $\mathrm{J}$ Biochem Cell Biol 2004;36:849-60.

33. Manning CB, Vallyathan V, Mossman BT. Diseases caused by asbestos: Mechanisms of injury and disease development. Int Immunopharmacol 2002;2:191-200.

34. Calandra T, Bernhagen J, Mitchell RA, Bucala R. The macrophage is an important and previously unrecognized source of macrophage migration inhibitory factor. J Exp Med 1994;179:1895-902.

35. Mitchell RA, Metz CN, Peng T, Bucala R. Sustained mitogenactivated protein kinase (mapk) and cytoplasmic phospholipase a2 activation by macrophage migration inhibitory factor (mif): Regulatory role in cell proliferation and glucocorticoid action. J Biol Chem 1999;274:18100-6.

36. Marsh LM, Cakarova L, Kwapiszewska G, Von Wulffen W, Herold S, Seeger W, et al. Surface expression of cd74 by type ii alveolar epithelial cells: A potential mechanism for macrophage migration inhibitory factor-induced epithelial repair. Am J Physiol Lung Cell Mol Physiol 2009;296:L442-52.

37. Morse D. The role of heme oxygenase-1 in pulmonary fibrosis. Am J Respir Cell Mol Biol 2003;29:S82-6.

38. Morse D, Lin L, Choi AMK, Ryter SW. Heme oxygenase-1, a critical arbitrator of cell death pathways in lung injury and disease. Free Radic Biol Med 2009;47:1-12.
39. Nagatomo H, Morimoto Y, Oyabu T, Hirohashi M, Ogami A, Yamato $\mathrm{H}$, et al. Expression of heme oxygenase-1 in the lungs of rats exposed to crocidolite asbestos. Inhal Toxicol 2005; 17:293-6.

40. Wu ML, Layne MD, Yet SF. Heme oxygenase-1 in environmental toxin-induced lung disease. Toxicol Mech Methods 2012;22:323-9.

41. Rapisarda V, Rapisarda G, Vico GD, Gobbi L, Loreto C, Valentino M. Monitoring of fluoro-edenite fibre pollution through the study of sheep lymph nodes as a model of a biological indicator. Occup Environ Med 2005;62:656.

42. Leonardi R, Almeida LE, Trevilatto PC, Loreto C. Occurrence and regional distribution of trail and $\mathrm{dr} 5$ on temporomandibular joint discs: Comparison of disc derangement with and without reduction. Oral Surg Oral Med Oral Pathol Oral Radiol Endod 2010;109:244-51.

43. Castorina A, Loreto C, Vespasiani G, Giunta S, Musumeci G, Castorina $\mathrm{S}$, et al. Increased aquaporin 1 expression in the tunica albuginea of peyronie's disease patients: An in vivo pilot study. Histol Histopathol 2016;31:1241-9.

44. Graziano ACE, Parenti R, Avola R, Cardile V. Krabbe disease: involvement of connexin43 in the apoptotic effects of sphingolipid psychosine on mouse oligodendrocyte precursors. Apoptosis 2016; 21:25-35.

45. Angelico G, Caltabiano R, Loreto C, Ieni A, Tuccari G, Ledda $\mathrm{C}$, et al. Immunohistochemical expression of aquaporin-1 in fluoro-edenite-induced malignant mesothelioma: A preliminary report. Int J Mol Sci 2018;19.

46. Musumeci G, Loreto C, Giunta S, Rapisarda V, Szychlinska MA, Imbesi R, et al. Angiogenesis correlates with macrophage and mast cell infiltration in lung tissue of animals exposed to fluoro-edenite fibers. Exp Cell Res 2016;346:91-8.

47. Musumeci G, Loreto C, Szychlinska MA, Imbesi R, Rapisarda $\mathrm{V}$, Aiello FC, et al. N-cadherin, adam-10 and aquaporin 1 expression in lung tissue exposed to fluoroedenite fibers: An immunohistochemical study. Histol Histopathol 2015;30:98799.

48. Caltabiano R, Loreto C, Vitale E, Matera S, Miozzi E, Migliore $\mathrm{M}$, et al. Fibulin-3 immunoexpression in malignant mesothelioma due to fluoro-edenite: A preliminary report. Future Oncol 2018;14:53-7.

49. Ledda C, Rapisarda V. Malignant pleural mesothelioma: The need to move from research to clinical practice. Arch Med Res 2016;47:407.

50. Ledda C, Senia P, Rapisarda V. Biomarkers for early diagnosis and prognosis of malignant pleural mesothelioma: The quest goes on. Cancers 2018;10. pii: E203.

51. Musumeci G, Cardile V, Fenga C, Caggia S, Loreto C. Mineral fibre toxicity: Expression of retinoblastoma (rb) and phosphoretinoblastoma (prb) protein in alveolar epithelial and mesothelial cell lines exposed to fluoro-edenite fibres. Cell Biol Toxicol 2011;27:217-25.

52. Musumeci G, Loreto C, Cardile V, Carnazza ML, Martinez G. Immunohistochemical expression of retinoblastoma and phospho-retinoblastoma protein in lung sheep exposed to fluoroedenite fibers. Anat Sci Int 2010;85:74-8.

53. Szychlinska MA, Parenti R, Loreto C, Salvatorelli L, Spadola $\mathrm{S}$, Trovato FM, et al. Fluoro edenite-associated pathogenesis in pleural malignant mesothelioma. Acta Med Mediter 2014;30:981-9.

54. Rapisarda V, Salemi R, Marconi A, Loreto C, Graziano ACE, Cardile V, et al. Fluoro-edenite induces fibulin-3 overexpression in non-malignant human mesothelial cells. Oncol Lett 2016;12:3363-7.

55. Begin R, Rola-Pleszczynski M, Sirois, Masse S, Nadeau D, 
Bureau MA. Sequential analysis of the bronchoalveolar milieu in conscious sheep. J Appl Physiol Respir Environ Exerc Physiol 1981;50:665-71.

56. Hardman MJ, Waite A, Zeef L, Burow M, Nakayama T, Ashcroft GS. Macrophage migration inhibitory factor: A central regulator of wound healing. Am J Pathol 2005;167:1561-74.

57. Abe R, Shimizu T, Ohkawara A, Nishihira J. Enhancement of macrophage migration inhibitory factor (mif) expression in injured epidermis and cultured fibroblasts. Biochim Biophys Acta 2000;1500:1-9.

58. Ashcroft GS, Mills SJ, Lei K, Gibbons L, Jeong MJ, Taniguchi $\mathrm{M}$, et al. Estrogen modulates cutaneous wound healing by downregulating macrophage migration inhibitory factor. J Clin Invest 2003;111:1309-18.

59. Matsuda A, Tagawa Y, Matsuda H, Nishihira, J. Expression of macrophage migration inhibitory factor in corneal wound healing in rats. Invest Ophthalmol Vis Sci 1997;38:1555-62.

60. Hudson JD, Shoaibi MA, Maestro R, Carnero A, Hannon GJ, Beach DH. A proinflammatory cytokine inhibits p53 tumor suppressor activity. J Exp Med 1999;190:1375-82.

61. Lue H, Thiele M, Franz J, Dahl E, Speckgens S, Leng L, et al. Macrophage migration inhibitory factor (mif) promotes cell survival by activation of the akt pathway and role for csn5/jab1 in the control of autocrine mif activity. Oncogene 2007;26:5046-59.

62. Oda S, Oda T, Nishi K, Takabuchi S, Wakamatsu T, Tanaka T, et al. Macrophage migration inhibitory factor activates hypoxia-inducible factor in a p53-dependent manner. PLoS One 2008;3(5):e2215.

63. Petrenko O, Moll UM. Macrophage migration inhibitory factor mif interferes with the rb-e2f pathway. Mol Cell 2005;17:22536.

64. Lee TC, Gold LI, Reibman J, Aston C, Bégin R, Rom WN, et al. Immunohistochemical localization of transforming growth factor- $\beta$ and insulin-like growth factor- $i$ in asbestosis in the sheep model. Int Arch Occup Environ Health 1997;69:157-64.

65. Chau LY. Heme oxygenase-1: Emerging target of cancer therapy. J Biomed Sci 2015;22:22.

66. Otterbein LE, Hedblom A, Harris C, Csizmadia E, Gallo D, Wegiel $\mathrm{B}$. Heme oxygenase-1 and carbon monoxide modulate dna repair through ataxia-telangiectasia mutated (atm) protein. Proc Natl Acad Sci USA 2011;108:14491-6.

67. Mayerhofer M, Florian S, Krauth MT, Aichberger KJ, Bilban $\mathrm{M}$, Marculescu R, et al. Identification of heme oxygenase-1 as a novel bcr/abl-dependent survival factor in chronic myeloid leukemia. Cancer Res 2004;64:3148-54.

68. Lin PH, Lan WM, Chau LY. Trc8 suppresses tumorigenesis through targeting heme oxygenase- 1 for ubiquitination and degradation. Oncogene 2013;32:2325-34.

69. Was H, Cichon T, Smolarczyk R, Rudnicka D, Stopa M, Chevalier $\mathrm{C}$, et al. Overexpression of heme oxygenase- 1 in murine melanoma: Increased proliferation and viability of tumor cells, decreased survival of mice. American Journal of Pathology 2006;169:2181-98.

70. Maines MD. Heme oxygenase: Function, multiplicity, regulatory mechanisms, and clinical applications. FASEB J 1988;2:2557-68.

71. Choi AMK, Alam J. Heme oxygenase-1: Function, regulation, and implication of a novel stress-inducible protein in oxidantinduced lung injury. Am J Respir Cell Mol Biol 1996;15:9-19.

72. Stocker R, Glazer AN, Ames BN. Antioxidant activity of albumin-bound bilirubin. Proc Natl Acad Sci USA1987;84:591822.

73. Stocker R, Yamamoto Y, McDonagh AF, Glazer AN, Ames BN Bilirubin is an antioxidant of possible physiological importance. Science 1987;235:1043-16.

74. Otterbein LE, Bach FH, Alam J, Soares M, Lu HT, Wysk M, et al. Carbon monoxide has anti-inflammatory effects involving the mitogen- activated protein kinase pathway. Nature Med 2000;6:422-8.

75. Shannahan JH, Ghio AJ, Schladweiler MC, McGee JK, Richards JH, Gavett SH, et al. The role of iron in libby amphibole-induced acute lung injury and inflammation. Inhal Toxicol 2011;23:313-23.

76. Nagatomo H, Morimoto Y, Oyabu T, Hirohashi M, Ogami A, Yamato H, et al. Expression of heme oxygenase-1 in the lungs of rats exposed to crystalline silica. J Occup Health 2006;48:124-8.

77. Hsu FF, Chiang MT, Li FA, Yeh CT, Lee WH, Chau LY. Acetylation is essential for nuclear heme oxygenase-1enhanced tumor growth and invasiveness. Oncogene 2017;36:6805-14.

78. Haegens A, Barrett TF, Gell J, Shukla A, MacPherson M, Vacek $\mathrm{P}$, et al. Airway epithelial $\mathrm{nf}-\kappa \mathrm{b}$ activation modulates asbestosinduced inflammation and mucin production in vivo. $\mathrm{J}$ Immunol 2007;178:1800-8.

Received for publication: 18 September 2019. Accepted for publication: 9 March 2020.

This work is licensed under a Creative Commons Attribution-NonCommercial 4.0 International License (CC BY-NC 4.0).

CCopyright: the Author(s), 2020

Licensee PAGEPress, Italy

European Journal of Histochemistry 2020; 64:3073

doi:10.4081/ejh.2020.3073 